\title{
Intragastric acidity as a predictor of the success of Helicobacter pylori eradication: a study in peptic ulcer patients with omeprazole and amoxicillin
}

\author{
J Labenz, M Stolte, A L Blum, I Jorias, F Leverkus, M Sollböhmer, J Bertrams, G Börsch
}

\begin{abstract}
Omeprazole plus amoxicillin cures Helicobacter pylori infection. The hypothesis was tested that low acidity is a predictor of outcome. Fifty patients with relapsing or complicated, or both $H$ pylori positive duodenal $(n=25)$ or gastric ulcer $(n=25)$ were randomly treated with either omeprazole $20 \mathrm{mg}$ twice daily plus amoxicillin $1 \mathrm{~g}$ twice daily or with omeprazole 40 mg twice daily plus amoxicillin $1 \mathrm{~g}$ twice daily over two weeks. After one week of combined treatment, a 24 hour gastric pH measurement was performed in all patients. $H$ pylori cure rate was $67 \%$. Patients who later turned out to be cured had higher $\mathrm{pH}$ values during night time and after meals $(p<0.05)$. In an explorative analysis drug compliance, smoking, location of the ulcer (duodenum versus stomach), age, and grade of body gastritis were additional predictors of the outcome. Smoking $(p=0 \cdot 006)$, compliance $(p=0.037)$, duodenal ulcer disease $(p=0.065)$, and young age $(p=0.021)$ were related to high acidity. In conclusion, the success of eradication treatment with omeprazole and amoxicillin in ulcer patients infected with $H$ pylori depends on intragastric pH. Drug compliance, smoking habits, location of ulcer, age, and activity of body gastritis are other predictors and in part related to intragastric acidity.

(Gut 1995; 37: 39-43)
\end{abstract}

Keywords: Helicobacter pylori, intragastric acidity, peptic ulcer, omeprazole, amoxicillin.

Simple and safe monotherapies with antibiotics have failed to cure most Helicobacter

pylori infections despite excellent in vitro efficacy. Recently, several studies showed that this therapeutic inefficacy might be overcome by coadministration of medium or high dose omeprazole. ${ }^{1-5}$ It is tempting to speculate that the hypoacidic gastric environment enhances the in vivo efficacy of the antibiotic.

To shed further light on the role of gastric acid inhibition in the treatment of $H$ pylori infection, we conducted this prospective randomised study in ulcer patients who received a two week treatment course with medium or high dose omeprazole plus amoxicillin. After one week of treatment 24 hour gastric $\mathrm{pH}$ measurement was performed.

\section{Methods}

\section{Patients}

Inclusion criteria were a history of endoscopically confirmed relapsing ulcer disease or ulcer complications (bleeding, perforation with simple closure), or both, endoscopic evidence of an active ulcer or a scarry deformation at the time of enrolment, $H$ pylori infection confirmed by histology or culture, or both, and an age above 18 years. Exclusion criteria were treatment with omeprazole, bismuth salts, or antibiotics during the past four weeks before entering the study, a history of ulcer surgery except simple closure of a perforation, decompensated gastric outlet obstruction, pregnancy or lactation period, renal insufficiency, congestive heart failure, severe liver disease, clotting disorder, known hypersensitivity against one of the study drugs, and suspected lack of compliance. Randomisation was performed with coded envelopes. One patient was excluded from the study because of suspected chronic alcoholism. Fifty $H$ pylori positive patients (inpatients: $n=15$; outpatients: $n=35$ ) with

\section{Division of}

Gastroenterology,

University Vaudois, Lausanne, Switzerland A Blum

Karlsruhe, Germany F Leverkus

\section{Department of} Laboratory Medicine, Elisabeth Hospital Essen, Germany J Bertrams

Correspondence to: Dr J Labenz, Department of Medicine, Elisabeth Hospital, Moltekestraße 61, D-45138 Essen, Germany. Accepted for publication 10 November 1994
TABLE I Demographic and clinical characteristics of the study patients

\begin{tabular}{|c|c|c|c|c|c|c|}
\hline & $\begin{array}{l}D U 40 \\
(n=12)\end{array}$ & $\begin{array}{l}D U 80 \\
(n=13)\end{array}$ & $\stackrel{p}{\text { Value }}$ & $\begin{array}{l}G U 40 \\
(n=13)\end{array}$ & $\begin{array}{l}G U 80 \\
(n=12)\end{array}$ & $\stackrel{p}{\text { Value }}$ \\
\hline Age, median (range), y & $51(27-73)$ & $44(32-79)$ & 0.61 & $63(43-72)$ & $58(28-72)$ & $0 \cdot 21$ \\
\hline Sex, $\mathrm{men} /$ women & $9 / 3$ & $9 / 4$ & $1 \cdot 00$ & $8 / 5$ & $8 / 4$ & 1.00 \\
\hline Smoker & 5 & 9 & $0 \cdot 24$ & 4 & 5 & 0.69 \\
\hline Regular alcohol use & 2 & 3 & $1 \cdot 00$ & 1 & 2 & 0.59 \\
\hline \multicolumn{7}{|l|}{ Ulcer disease } \\
\hline History, median (range), y & $7 \cdot 5(0-37)$ & $11(0-32)$ & 0.43 & $15(0-43)$ & $4 \cdot 5(0-20)$ & $0 \cdot 10$ \\
\hline Ulcer disease in remission & & 3 & $1 \cdot 00$ & 1 & 2 & 0.59 \\
\hline Complicated ulcer disease & 5 & 4 & 0.69 & 5 & 3 & 0.67 \\
\hline \multicolumn{7}{|l|}{ Antral gastritis } \\
\hline Grade, median (range) & $3 \cdot 5(3-4)$ & $3(3-4)$ & 1.00 & $3(3-4)$ & $3(2-4)$ & 0.55 \\
\hline Activity, median (range) & $3 \cdot 5(3-4)$ & $3(2-4)$ & 0.07 & $3(2-4)$ & $3 \cdot 5(1-4)$ & $0 \cdot 47$ \\
\hline \multicolumn{7}{|l|}{ Body gastritis } \\
\hline Grade, median (range) & $2(2-3)$ & $2(1-3)$ & $0 \cdot 16$ & $3(2-4)$ & $2(2-3)$ & $0 \cdot 31$ \\
\hline Activity, median (range) & $2(1-3)$ & $1(0-3)$ & 0.04 & $2(1-4)$ & $2(1-3)$ & $0 \cdot 14$ \\
\hline
\end{tabular}

DU: duodenal ulcer; GU: gastric ulcer; 40: $40 \mathrm{mg}$ omeprazole per day; 80: $80 \mathrm{mg}$ omeprazole per day. 
TABLE II Overview of the clinical treatment results in duodenal and gastric ulcer patients

\begin{tabular}{|c|c|c|c|c|c|c|}
\hline & $D U 40$ & $D U 80$ & p Value & $G U 40$ & $G U 80$ & p Value \\
\hline $\begin{array}{l}\text { Patients treated } \\
\text { Lost to follow up }\end{array}$ & $\begin{array}{r}12 \\
1\end{array}$ & $\begin{array}{r}13 \\
0\end{array}$ & & $\begin{array}{r}13 \\
0\end{array}$ & $\begin{array}{r}12 \\
0\end{array}$ & \\
\hline Sufficient compliance ${ }^{\star}$ & $9 / 11$ & $10 / 13$ & 1.00 & $13 / 13$ & $11 / 12$ & 0.48 \\
\hline Cure of $H$ pylori infection (\%) & $7 / 11(63.6)$ & $5 / 13(38 \cdot 5)$ & 0.41 & $11 / 13(84 \cdot 6)$ & $10 / 12(83 \cdot 3)$ & 1.00 \\
\hline Ulcer healing after 6 weeks $(\%)$ & $8 / 9(88.9) \dagger$ & $9 / 10(90 \cdot 0)$ & 1.00 & $12 / 12(100)$ & $9 / 10(90)$ & 0.45 \\
\hline Side effects (\%) & $1 / 11(9 \cdot 1)$ & $1 / 13(7 \cdot 7)$ & 1.00 & $2 / 13(15 \cdot 4)$ & $0 / 12(0)$ & 0.48 \\
\hline Discontinuation of treatment $(\%)$ & $2(18 \cdot 1) \ddagger$ & 0 & & 0 & 0 & \\
\hline
\end{tabular}

$\star>90 \%$ intake of the prescribed study drugs; †treatment failure associated with aspirin consumption; $\neq$ treatment stopped because of side effects $(n=1)$ and insufficient compliance $(n=1)$.

relapsing or complicated duodenal ulcer disease, or both $(n=25$; Table I) or gastric ulcer disease $(n=25$; Table I) qualified for admission to the study. They were randomly assigned to receive either omeprazole $20 \mathrm{mg}$ twice daily $(n=25)$ or omeprazole $40 \mathrm{mg}$ twice daily $(n=25)$ for two weeks. Omeprazole was given before breakfast and dinner. All patients received amoxicillin $1 \mathrm{~g}$ twice daily after breakfast and dinner. Treatment was continued with omeprazole $20 \mathrm{mg}$ before breakfast during the subsequent four weeks.

Before enrolment patients were instructed orally and with an information sheet about the basic concepts of the role of $H$ pylori infection in peptic ulcer disease, and all gave informed consent.

\section{Study design}

Before starting treatment and after six weeks, an upper gastrointestinal endoscopy was performed. Four biopsy specimens from the antrum and four specimens from the corpus were taken. $H$ pylori infection was assessed by means of an urease test (Jatrox Hp Test, Röhm Pharma, Weiterstadt, Germany), specific culture, and histological assessment of WarthinStarry stains. ${ }^{6}$ Antral and body gastritis were graded according to the Sydney system with haematoxylin and eosin stains. ${ }^{6}$ Four to six

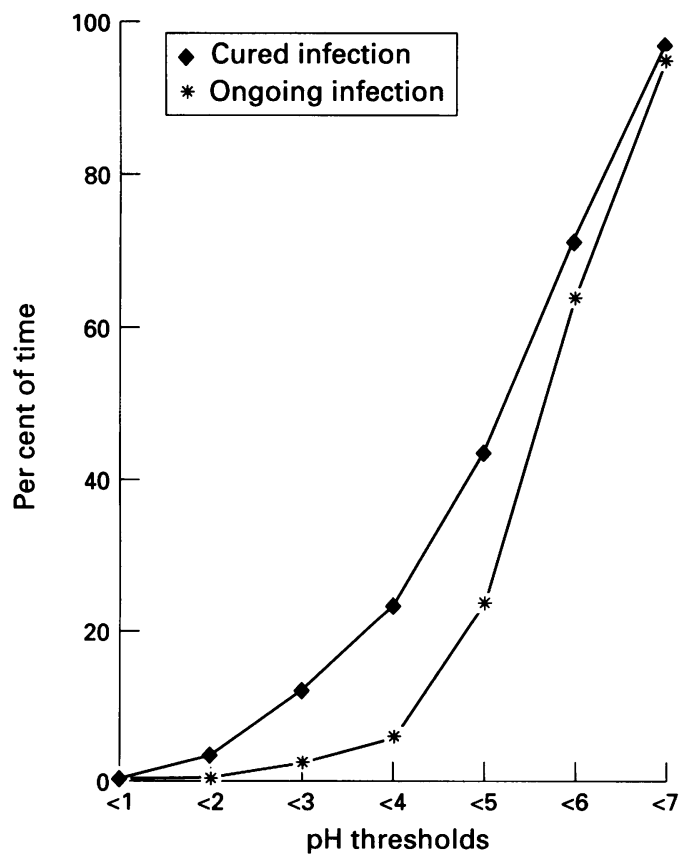

Medians of the per cent of time spent below distinctive $p H$ thresholds in patients with and without cure of $\mathrm{H}$ pylori infection. weeks after endoscopically confirmed complete ulcer healing and the finish of all antiulcer treatment, a sensitive and specific ${ }^{13} \mathrm{C}$ urea breath test was performed. ${ }^{6}$ Blinding was performed by coding the biopsy vials and the vacutainers. Cure of $H$ pylori infection (eradication) was defined as no evidence of ongoing $H$ pylori infection with all four methods mentioned. Ongoing $H$ pylori infection was assumed when at least one of the four methods indicated persistent bacterial colonisation.

After one week of combined omeprazole/ amoxicillin treatment a 24 hour gastric $\mathrm{pH}$ measurement was performed in all patients. An Ingold glass electrode (440-M3, Medical Instruments Corporation (MIC), Solothurn, Switzerland) was placed $5 \mathrm{~cm}$ below the cardia. The correct position was controlled fluoroscopically. At the beginning and at the end of each examination, the electrode was accurately calibrated using buffer solutions of pH 4.01 and 7.00 (Fresenius AG, Bad Homburg, Germany). Faulty electrodes with drifts of more than $0.2 \mathrm{pH}$ units were discarded. The $\mathrm{pH}$ values were recorded (four times per second with internal data reduction to the medians of two second intervals) with a GastrograpH Mark III (Fresenius AG, Bad Homburg, Germany) starting at 10 am. Patients received three standardised meals during the following 24 hours ( $100 \mathrm{pm}, 700$ pm, $730 \mathrm{am}$ ). Extra food was not permitted. In addition, all patients recorded the exact time of drug consumption, meals, body position (upright or supine), and the number of cigarettes consumed in a diary. The raw $\mathrm{pH}$ data were transferred to a MS-DOS personal computer and analysed with the 'pack 2' software (MIC, Solothurn, Switzerland).

Patients compliance was checked with a diary and by counting the returned tablets. Sufficient compliance was defined as a consumption of more than $90 \%$ of the delivered drugs during the two weeks of combined omeprazole plus amoxicillin treatment. In addition, the complaints resulting from peptic ulcer disease and adverse events were recorded in the diary.

Statistical comparisons of the demographic and clinical data and treatment results of the study groups (duodenal ulcer treated with omeprazole $40 \mathrm{mg}$, duodenal ulcer treated with omeprazole $80 \mathrm{mg}$, gastric ulcer treated with omeprazole $40 \mathrm{mg}$, gastric ulcer treated with omeprazole $80 \mathrm{mg}$ ) as well as of the $\mathrm{pH}$ metry analyses were performed with Mann-Whitney $U$ test (steady data), $\chi^{2}$ test or Fisher's exact test 
TABLE III Factors associated with outcome (cure of $\mathrm{H}$ pylori infection) in univariate and multiple regression analyses

\begin{tabular}{|c|c|c|c|c|c|c|}
\hline \multirow[b]{2}{*}{ Factors } & \multirow{2}{*}{$\begin{array}{l}\text { Cure } \\
(n=33)\end{array}$} & \multirow{2}{*}{$\begin{array}{l}\text { No cure } \\
(n=16)\end{array}$} & \multirow[b]{2}{*}{ p Value } & \multicolumn{3}{|c|}{ Results of multiple regression analysis } \\
\hline & & & & p Value & Odds ratio & $90 \% C I$ \\
\hline Compliance $+/-$ & $33 / 0$ & $10 / 6$ & $<0.001$ & & & \\
\hline Smoking $+1-$ & $9 / 24$ & $13 / 3$ & 0.001 & 0.035 & 5.09 & 1.43 to $18 \cdot 16$ \\
\hline Median time spent below pH $4(\%)$ & $6 \cdot 0$ & $23 \cdot 65$ & 0.013 & 0.052 & $2 \cdot 21$ & $1 \cdot 13$ to 4.34 \\
\hline Duodenal ulcer/gastric ulcer & $12 / 21$ & $12 / 4$ & 0.011 & 0.077 & 3.98 & $1 \cdot 10$ to 14.38 \\
\hline Age, median (range), y & $60(28-79)$ & $45(27-72)$ & 0.020 & & & \\
\hline Grade of body gastritis & $3(2-4)$ & $2(1-3)$ & 0.023 & & & \\
\hline
\end{tabular}

CI: confidence intervals.

(nominal data), if appropriate, and with the Mantel-Haenszel text (categorial data). All analyses were two tailed. Statistical significance was considered at a $5 \%$ probability value.

An exploratory analysis of all conceivable predictors of the success of treatment ( $H$ pylori eradication $v H$ pylori persistence) was performed using the SAS program (SAS Institute, Cary, NC). Patients were categorised into three groups (20-40, 41-60, >60) according to the age. In a first step, an univariate analysis was done with $\chi^{2}$ test (sex, compliance, smoking, alcohol use, outpatient/inpatient, use of aspirin or non-steroidal anti-inflammatory drug (NSAID), dose of omeprazole, active ulcer/ulcer disease in remission, occurrence of side effects, pain at the time of enrolment, ulcer location (duodenal ulcer/gastric ulcer), complicated ulcer disease), a Mantel-Haenszel test (grade and activity of antral and of body gastritis, age categories), or a Mann-Whitney $\mathrm{U}$ test (duration of the peptic ulcer disease history). In a second step, a multiple logistic regression analysis was used to identify the variables having the strongest relation with success. In a third step, the correlations of the variable 'per cent time spent below $\mathrm{pH} 4$ ' to the other identified variables influencing the treatment success were assessed using the Mantel-Haenszel test with ridit scores.

\section{Results}

Fifty patients with duodenal $(n=25)$ or gastric ulcer disease $(n=25)$ entered the study. $H$ pylori infection was confirmed histologically and with the urease test in all patients and culturally in 48 of 50 patients. The two groups (DU 40 and DU 80) of patients with duodenal ulcer disease (Table I) as well as the two groups of patients with gastric ulcer disease (GU 40 and GU 80) had similar demographic and clinical characteristics (age, sex, height, body weight, nationality, smoking and drinking habits, aspirin or NSAID use, ulcer disease history, ulcer size, number of ulcers, pain score, and gastritis scores except a statistically significant lower grade of activity of the body gastritis in duodenal ulcer patients subsequently treated with $80 \mathrm{mg}$ omeprazole per day). One patient of the duodenal ulcer group (DU 40) refused control endoscopy ('lost to follow up'). A patient of the same group stopped the amoxicillin treatment after 10 days because of an exanthema. Another patient stopped amoxicillin after 11 days because of lack of compliance.

The overall cure rate of $H$ pylori infection was $67 \%$ (33 of 49 patients). There was a statistically significant difference between duodenal and gastric ulcer patients $(50 \% v$ $84 \%, \mathrm{p}<0.011)$. The proportion of eradication tended to be higher in duodenal ulcer patients treated with $40 \mathrm{mg}$ omeprazole plus amoxicillin compared with the $80 \mathrm{mg}$ omeprazole schedule, but the difference did not reach statistical significance $(63.6 \% v 38.5 \%$, $\mathrm{p}=0 \cdot 41)$. The patients with gastric ulcer disease responded similarly to the medium and the high dose omeprazole schedule (Table II). Complete ulcer healing was endoscopically confirmed after six weeks in 38 of 41 patients with active ulcer disease at the time of enrolment. The study treatment was well tolerated in most of the treated patients. Four patients ( $8 \%$ of the total study group) complained of side effects resulting from the amoxicillin treatment (exanthema: $n=2$, mouth burning/ stomatitis: $n=2$ ). In only one patient antibiotics had to be stopped after 10 days. Nevertheless, $H$ pylori infection was cured in this case.

In patients with a successful cure of $H$ pylori infection gastric $\mathrm{pH}$ was higher during the entire 24 hour period (median gastric $\mathrm{pH}$ ( $10 \%$ percentile to $90 \%$ percentile): 5.5 $(4 \cdot 2-6 \cdot 2) v 5 \cdot 0(3.5-5 \cdot 9), \mathrm{p}=0.0365)$, during night time (10 pm to $6 \mathrm{am}$ ) (median gastric $\mathrm{pH}$ $(10 \%$ percentile to $90 \%$ percentile): $6 \cdot 3$ $(4 \cdot 0-6 \cdot 9)$ v 5.5 $(2 \cdot 1-6 \cdot 4), \mathrm{p}=0.0254)$, and after meals (breakfast, supper) (median gastric $\mathrm{pH}(10 \%$ percentile to $90 \%$ percentile $): 5 \cdot 3$ $(3.8-6.0) v 4.75(3.25-6.4), \mathrm{p}=0.0473)$, and a decrease of time spent below pH 2,3,4, and 5 was observed (Figure; $p<0 \cdot 05$ ). There was no statistically significant difference of the median gastric $\mathrm{pH}$ during daytime (median gastric $\mathrm{pH}$ ( $10 \%$ percentile to $90 \%$ percentile): 5.5 $(4 \cdot 1-6 \cdot 1)$ v 5.2 (3.6-5.9), $\mathrm{p}=0 \cdot 1052)$. A clear cut off point discriminating patients with treatment failure from patients experiencing treatment success does not exist.

The relation between outcome, demographic, and clinical characteristics was subjected to an exploratory analysis. Eradication correlated with drug compliance, smoking, location of the ulcer, age, and grade of body gastritis in an univariate analysis (Table III), while sex $(p=0 \cdot 148)$, duration of ulcer disease history $(p=0.949)$, complicated ulcer disease $(p=0.117)$, ulcer disease in remission $(p=0.614)$, pain at the time of enrolment $(p=0.174)$, grade of antral gastritis $(p=0.118)$, and activity of antral and body gastritis $(p=0.841$ and $p=0.472$, respectively), intake of aspirin or NSAID $(p=0.058)$, alcohol consumption $(p=0.749)$, pre-treatment with antacids or $\mathrm{H}_{2}$ blockers $(p=1 \cdot 00)$, stay in hospital $(p=0 \cdot 168)$, and 
dose of omeprazole $(p=0 \cdot 263)$ were not related to outcome.

Patients with and without active ulcer at the time of enrolment did not differ with regard to ulcer symptoms (epigastric pain: $p=0 \cdot 25$ ), grade and activity of antral gastritis $(p=0.31$ and $p=0 \cdot 28$, respectively), grade and activity of body gastritis $(p=0.25$ and $p=0.63$, respectively), and gastric acidity (per cent of time spent below pH 4: $p=0 \cdot 68$ ).

The best predictor of outcome was drug compliance. All patients with insufficient compliance showed ongoing $H$ pylori infection at the final follow up examination. The predictor compliance could not be tested in a multiple logistic regression analysis because of lack of convergence of the likelihood. Of the remaining parameters smoking, per cent time spent below $\mathrm{pH} 4$, and ulcer location (gastric ulcers responded better than duodenal ulcer) were independent predictors of the treatment success (Table III). Gastric acidity reduction depended on smoking, compliance, location of the ulcer, and age. More time was spent below $\mathrm{pH} 4$ in smokers $(\mathrm{p}=0.006)$, non-compliant patients $(p=0.037)$, young patients $(p=0.021)$, and duodenal ulcer patients $(p=0.065)$. Gastric acidity was not related to grade $(p=0.81)$ and activity of body gastritis $(\mathrm{p}=0 \cdot 19)$.

\section{Discussion}

We have performed eradication treatment consisting of omeprazole and amoxicillin in ulcer patients infected with $H$ pylori and shown that the success depended on intragastric $\mathrm{pH}$; a higher $\mathrm{pH}$ was associated with a higher rate of success. Patients who later turned out to be cured had a median gastric $\mathrm{pH}$ of 5.5 while patients with persisting infection had a $\mathrm{pH}$ of $5 \cdot 0$. A weakness of our study is the fact that baseline $\mathrm{pH}$ measurements are not available. These will be included in future studies. Irrespective of the unknown baseline results, the $\mathrm{pH}$ values recorded after one week of eradication treatment will in all likelihood be best suited to decide whether or not intragastric $\mathrm{pH}$ is really a predictor of outcome of omeprazole/amoxicillin treatment of $H$ pylor infection.

A high $\mathrm{pH}$ may augment the effect of amoxicillin by various mechanisms: it may lower the minimal inhibitory concentration values of this $\mathrm{pH}$ dependent antibiotic, ${ }^{7}$ increase stability of the antibiotic in gastric juice, ${ }^{8}$ and increase its luminal concentration by slowing gastric emptying ${ }^{9}$ or lowering the dilution volume. ${ }^{10} \mathrm{~A}$ high $\mathrm{pH}$ may also have other effects favouring eradication such as interfering with the adherence of $H$ pylori (Blum AL, unpublished data), the creation of an environment that permits overgrowth of bacterial competitors ${ }^{11}$ or improving the stability of luminal immunoglobulins. ${ }^{12} \mathrm{We}$ could not demonstrate an effect of the dose of omeprazole on the cure rates when omeprazole was combined with amoxicillin in duodenal and gastric ulcer patients ${ }^{13}{ }^{14}$; other authors have reported a dose dependence of the cure rates when omeprazole was combined with amoxicillin or clarithromycin. ${ }^{1516}$ Factors other than ulcer location that influenced gastric acidity were smoking, compliance, and young age. All these factors were not only associated with intragastric acidity, but also with the success of eradication treatment.

It has recently been shown that omeprazole has a stronger antisecretory effect in subjects infected with $H$ pylori than in non-infected subjects. ${ }^{17}$ As in our study $\mathrm{pH}$ metries were performed one week after the start of the antibiotic treatment, it is probable that many of the successfully treated patients had already cleared their infection and that omeprazole thus may have lost some of its effectiveness. It is therefore probable that the $\mathrm{pH}$ difference between cured and uncured patients would have been even more pronounced if we had performed $\mathrm{pH}$ metry at the beginning of treatment - that is, when all patients were still infected. This hypothesis will be tested in future studies. On the other hand, duodenal ulcer patients infected with $H$ pylori have a sixfold increase in both basal and gastrin releasing peptide stimulated acid output, which fully resolves after eradication of the bacteria, but takes up to one year to do so. ${ }^{18}$

We performed an exploratory analysis of other predictors to further test the importance of acidity as a predictor of success. Thus, it was shown that the most important predictor was the compliance. Other predictors were smoking (non-smokers responded better than smokers), the location of the ulcer (gastric ulcers responded better than duodenal ulcers), age (eradication rates were higher in old patients than in young patients), and the grade of gastritis in the body (eradication was more frequent when gastritis was more severe). As several of these predictors were also related to gastric acidity, it might be hypothesised that the predictors of $H$ pylori eradication have, as a common denominator, an effect on acidity. Other types of anti- $H$ pylori treatment, however, seem not to require a reduction of gastric acidity. ${ }^{19}$ This may imply that our finding is related to the particular type of antibiotic, amoxicillin, which we have used. As, on the other hand, $H$ pylori is an acidophilic organism, it will have to be examined whether any type of treatment profits, to some extent, from acid reduction.

We have used two different doses of omeprazole $(20 \mathrm{mg}$ twice daily, $40 \mathrm{mg}$ twice daily) to show a difference in acid suppression. Surprisingly, duodenal ulcer patients treated with $40 \mathrm{mg}$ or $80 \mathrm{mg}$ omeprazole showed similar gastric $\mathrm{pH}$ patterns with regard to the median $\mathrm{pH}(5.35 v 5.30, \mathrm{p}=0.83)$ as well as to per cent of time spent below distinctive $\mathrm{pH}$ thresholds. On the other hand, patients suffering from gastric ulcer disease responded somewhat better to the higher dose of omeprazole reaching statistical significance (median $\mathrm{pH}$ : $5.95 v 5.30, \mathrm{p}=0.01) .{ }^{20}$

The overall proportion of $H$ pylori eradication in this study was $67 \%$ (95\% confidence intervals: $52 \%$ to $80 \%$ ), which is somewhat less than previously published by our 
group. ${ }^{31314}$ The major drawback of dual therapy comprising omeprazole and amoxicillin is inconsistency of treatment results. ${ }^{21} 22$ The published eradication rates varied between $0 \%$ and $91 \%$. We have recently statistically analysed our data from 405 patients having been treated with omeprazole plus amoxicillin and have shown by means of multiple logistic regression analysis that lack of compliance, short treatment duration, smoking, and pretreatment with omeprazole were independent risk factors for treatment failure, while old age, gastric ulcer disease, and high scores of grade and of activity of gastritis were independently associated with treatment success. ${ }^{23}$ In addition, Unge and coworkers have also shown that smoking is an important predictor of outcome and that smoking was frequently associated with poor compliance. ${ }^{5}$ As in this study compliance could not be tested by regression analysis, smoking may have been a confounding variable. Interestingly, a paper by Zala showed that the deleterious effect of smoking can be abolished by concomitant administration of acetylcysteine clearly suggesting that other factors (for example, free radicals in the stomach of smokers) than higher acidity and poor compliance might be important. ${ }^{24}$ In this study, the $H$ pylori eradication rate was very low in duodenal ulcer patients treated with omeprazole $80 \mathrm{mg}$ per day plus amoxicillin ( $H$ pylori cure rate: $38.5 \%$ (95\% confidence intervals: $14 \%$ to $68 \%$ )). Three of these 13 patients had insufficient compliance and nine were smokers. In addition, the scores of body gastritis in this group of patients were lower compared with the group of duodenal ulcer patients having been treated with omeprazole $40 \mathrm{mg}$ per day plus amoxicillin. Less severe body gastritis may theoretically account for an increased acid secretion that has been shown to be a significant predictor of outcome by multiple regression analysis, but our statistical analyses failed to detect a significant relation of grade and of activity gastritis to gastric acidity measured after one week of omeprazole/amoxicillin treatment.

1 Bayerdörffer E, Mannes GA, Sommer A, Höchter W, Weingart J, Hatz R, et al. High dose omeprazole treatmen combined with amoxicillin eradicates Helicobacter pylori European fournal of Gastroenterology and Hepatology 1992; 4: 697-702.

2 Labenz J, Gyenes E, Rühl GH, Börsch G. Omeprazole plus amoxicillin: efficacy of various treatment regimens to eradicate Helicobacter pylori. Am $\mathcal{F}$ Gastroenterol 1993; 88: 491-5.

3 Labenz J, Gyenes E, Rühl GH, Börsch G. Amoxicillin plus omeprazole versus triple therapy for eradication of
Helicobacter pylori in duodenal ulcer disease: a prospective, randomized, and controlled study. Gut 1993; 34: 1167-70. 4 Logan RPH, Gummett PA, Hegarty BT, Walker MM Baron JH, Misiewicz JJ. Clarithromycin and omeprazole for Helicobacter pylori. Lancet 1992; 340: 239.

5 Unge P, Gad A, Eriksson K, Bergman B, Carling L, Ekström $\mathrm{P}$, et al. Amoxicillin added to omeprazole prevents relapse in the treatment of duodenal ulcer patients. European fournal of Gastroenterology and Hepatology 1993; 5: 325-31.

6 Labenz J, Stolte M, Aygen S, Hennemann O, Bertrams J, Börsch G. Qualitative and semiquantitative invasive and non-invasive assessment of Helicobacter pylori colonisation non-invasive assessment of Helicobacter pylori colonisation

of the gastric mucosa. $Z$ Gastroenterol 1993; 31: 437-43.
Grayson ML, Eliopoulos GM, Ferraro MJ, Moellering Jr RC. Effect of varying $\mathrm{pH}$ on the susceptibility of Campylobacter pylori to antimicrobial agents. Eur $\mathcal{f}$ Clin Microbiol Infect Dis 1989; 8: 888-9.

8 Mainguet P, Delmee M, Debongnie JP. Omeprazole, Campylobacter pylori, and duodenal ulcer. Lancet 1989; ii: $389-90$.

9 Atherton JC, Washington N, Bracewell MA, Sutton LJ, Greaves JL, Perkins AC, et al. The effect of omeprazole on the gastric emptying of an encapsulated drug and of a the gastric emptying of an encapsulated drug

10 voderholz WA, Klauser AG, Mühldorfer BE, Müller-Lissner SA. Effect of gastric secretory inhibitors and cisapride on gastric volume in healthy volunteers. European fournal of Gastroenterology and Hepatology 1992; 4: 635-8.

11 Verdu E, Viani F, Armstrong D, Fraser R, Siegrist HH, Pignatelli $\mathrm{B}$, et al. Effect of omeprazole on intragastric bacterial counts, nitrates, nitrites, and $\mathrm{N}$-nitroso compounds. Gut 1994; 35: 455-60.

12 Hunt RH. $\mathrm{pH}$ and $\mathrm{Hp}$ - gastric acid secretion and Helicobacter pylori: implications for ulcer healing and eradication of the organism. Am $\mathcal{f}$ Gastroenterol 1993; 88: 481-3.

13 Labenz J, Rühl GH, Bertrams J, Börsch G. Medium- or high-dose omeprazole plus amoxicillin eradicates Helicobacter pylori in gastric ulcer disease. $A m \mathcal{F}$ Helicobacter pylori in gastric
Gastroenterol 1994; 89: 726-30.

14 Labenz J, Rühl GH, Bertrams J, Börsch G. Medium- and high-dose omeprazole plus amoxicillin for eradication of Helicobacter pylori in duodenal ulcer disease. Dig Dis $S c i$ 1994; 39: 1483-7.

15 Mannes GA, Bayerdörffer E, Hele C, Ruckdeschel G, Stolte $M$. An increasing dose of omeprazole combined with amoxicillin increases the eradication rate of Helicobacter pylori. Gastroenterology 1993; 104: A140.

16 Schauffelberger H, Logan RPH, Misiewicz J, Gummett $P$, Karim QN, Walker M, et al. The dose and frequency of omeprazole are important in treating $\mathrm{H}$ pylori with dual therapy. Gastroenterology 1993; 104: A186.

17 Armstrong D, Verdu E, Fraser R, Viani F, Idstöm JP, Cederberg C, et al. Helicobacter pylori infection augments the antisecretory effect of omeprazole. Acta Gastroenterol the antisecretory effect of
Belg 1993; 56 (suppl): 129.

$18 \mathrm{McColl} \mathrm{KEL,} \mathrm{El-Omar} \mathrm{E.} \mathrm{Effect} \mathrm{of} \mathrm{H}$ pylori infection on gastrin and gastric acid secretion. In: Hunt RH, Tytgat GNJ, eds. Helicobacter pylori. Basic mechanisms to clinical cure. Dordrecht: Kluwer Academic, 1994: 245-56.

19 Hosking SW, Ling TKW, Chung SCS, Yung CMY, Cheng AFB, Sung JJY, et al. Duodenal ulcer healing by eradication of Helicobacter pylori without anti-acid treatment: randomised controlled trial. Lancet 1994; 343: 508-10.

20 Labenz J, Jorias I, Sollböhmer M, Peitz U, Stolte M, Börsch G. 24-hour gastric $\mathrm{pH}$ pattern in patients with Helicobacter pylori associated gastroduodenal ulcer disease treated with omeprazole $20 \mathrm{mg}$ b.i.d. or $40 \mathrm{mg}$ b.i.d. daily. $Z$ Gastroenterol 1994; 32: 436-40.

21 Penston JG. Helicobacter pylori eradication - understandable caution but no excuse for inertia. Aliment Pharmacol Ther 1994; 8: 369-89.

22 Tytgat GNJ. Treatments that impact favourably upon the eradication of Helicobacter pylori and ulcer recurrence. Aliment Pharmacol Ther 1994; 8: 359-68.

23 Labenz J, Leverkus F, Börsch G. Omeprazole plus amoxicillin for cure of Helicobacter pylori infection. Factors influencing the treatment success. Scand $\mathcal{f}$ Gastroenterol 1994; 29: 1070-5.

24 Zala G, Flury R, Wüst J, Meyenberger C, Ammann R, Wirth HP. Omeprazol/amoxicillin: verbesserte Eradikation von Helicobacter pylori bei Rauchern durch N-Acetylcystein. Schweiz Med Wochenschr 1994; 124: 1391-7. 